Article

\title{
Switching Arc Energy Limitation Approach for LV Circuit Breakers
}

\author{
Dariusz Smugala $^{1, *(D)}$ and Michal Bonk ${ }^{2}$ (D) \\ 1 Department of Electrical Engineering, Faculty of Electrical and Computer Engineering, \\ Cracow University of Technology, Warszawska 24 Str., 31-155 Cracow, Poland \\ 2 Department of Electrical and Power Engineering, Faculty of Electrical Engineering, Automatics, \\ Computer Science and Biomedical Engineering, AGH University of Science and Technology, \\ Mickiewicza 30 Str., 30-059 Cracow, Poland; bonkm@agh.edu.pl \\ * Correspondence: dariusz.smugala@pk.edu.pl; Tel.: +48-604-554-884
}

check for updates

Citation: Smugala, D.; Bonk, M. Switching Arc Energy Limitation Approach for LV Circuit Breakers. Energies 2021, 14, 6774. https:// doi.org/10.3390/en14206774

Academic Editor: Mario Marchesoni

Received: 23 September 2021

Accepted: 14 October 2021

Published: 17 October 2021

Publisher's Note: MDPI stays neutral with regard to jurisdictional claims in published maps and institutional affiliations.

Copyright: (C) 2021 by the authors. Licensee MDPI, Basel, Switzerland. This article is an open access article distributed under the terms and conditions of the Creative Commons Attribution (CC BY) license (https:// creativecommons.org/licenses/by/ $4.0 /)$.
Abstract: This paper presents an experimentally verified approach to deriving switching arc energy limitations for low-voltage (LV) circuit breakers (CBs). Air-insulated contactors equipped with additional vacuum-insulated (VI) arcing contacts were tested for AC and DC current interruption efficiency, respectively. In the study, the contact arrangements of reed relay VI contact switches of low current breaking capacity combined with air-insulated contactors were examined. Tests were performed on selected LV CBs inductively loaded for LV power network rated voltages. A comparative analysis of the arc energy resulting from various arc time durations recorded during the switching-off operation was performed. Using a variety of either basic CB air-insulated contact systems or combined contact systems, a practical assessment of the proposed idea for enhancing the arc quenching efficiency was undertaken. As a result of the implementation of the proposed idea, the arc burning duration time was indicated as being hundreds of times shorter. In most cases, a complete arc reduction was achieved. Moreover, the resulting arc energy dissipation during the breaking operation was substantially minimized. Consequently, a significant increase in the total current breaking capacity of the tested CBs was achieved.

Keywords: circuit breakers; current interrupters; arc energy; arcing time; arc quenching; arc limitation; breaking capacity

\section{Research Topics}

Two leading directions in low-voltage (LV) circuit breaker (CB) development currently exist. One is manufacturing cost reduction combined with a simplification of the manufacturing process. The second is a functionality and operational efficiency extension. Assuming this line of reasoning, circuit breaker development can be implemented by either improving classic mechanical and electromechanical constructions or by marketing devices, the operation of which is through altered principles.

The development of CBs composed of traditional, mechanical contacts is especially difficult due to their relatively complex mechanical structure, and it is hard to expand their performance without significant increases in manufacturing costs [1-3]. Nevertheless, enhancement of the efficiency of such devices can be achieved through recognized conventional engineering. Enhancing the efficiency of CBs can be realized via manufacturers cooperating with researchers. The advancement of current interrupter (CI) types requires the collaboration of scientists from various fields of science [4-6].

This altered path to extending the performance and efficiency of LV switching devices is found by utilizing semiconductive switching devices to replace classic CBs equipped with mechanical contacts. This has resulted in solid-state (SS) switches and hybrid constructions.

Such devices function by means of: 
- Semiconductive element application, where the main switching branch consists of transistors, thyristors, triacs, and so on, and realizes the function of the main valve [7-11];

- Switching off by counter-current application methods [12];

- $\quad$ Passive component application for arc energy absorption (e.g., capacitors) [13].

Despite the fact that the use of modern SS switches comes with many benefits, and, in general, has positive effects on the reliability of the switching devices, CBs with mechanical contacts have some essential advantages that cannot be ignored. Switching devices containing mechanical contacts are irreplaceable, especially in power networks where visible galvanic separation between two circuits is required.

Unlike SS switches, current interrupters equipped with mechanical contact systems are indispensable in situations wherein the presence of non-linear elements generate negative effects during switching operations [14-16]. Moreover, in inductive or capacitive loaded circuits, the volume of energy dissipated during the high-current switching process excludes the application of SS CIs, as the high voltage and current surges taking place during these procedures may lead to failure both of passive and active power network components [17]. Thus, high temperature generation resulting from current flow and high frequency and a high rate of voltage surges significantly limits the number of possible SS switch applications.

For this reason, alternative methods of development for classic LV CBs and efficiency increases are often implemented. For example, mechanical or electromechanical switching devices are now being equipped with electronic control modules. However, the main switching part of the circuit breaker remains unchanged, as the addition of a control circuit is intended only to improve the operation of the applied drive. As a result, the current switching procedure is realized more quickly, and the negative effects that are the outcome of current interruption are limited [18-21].

A further method for increasing the efficiency of CBs is "zero-synchronized" switching (ZSS). Depending on the application, voltage-zero synchronization (VZS) on contact initiation or current-zero synchronization (CZS) during contact breaking is applied [22,23]. Unfortunately, the ZSS method is characterized as being difficult to implement and costly, as CIs must be combined with control units (CUs) that are optimized for a specific switching apparatus, while specific algorithms must be applied for predicting the upcoming switching operation parameters.

The application of such complicated systems for LV CIs seems to be unreasonable, as the costs of applying such CSs exceed the costs of providing a main switch. Thus, ZSS is usually implemented only in medium and high-voltage (MV, HV) power networks.

The primary methods of estimating the breaking capacity of circuit breakers are measuring the switching arc time duration and estimating the arc energy generated during the switching-off operation.

Upon a review of the current literature, the procedures for estimating current breaking capacity by way of measuring the arcing time $\left(T_{a}\right)$ or the switching arc energy $\left(E_{a}\right)[24]$ were found to be the most used in practice. Beyond the aforementioned, several different known methods of measuring $T_{a}$ and $E_{a}$ quantities can be applied. A common feature of these methods is that all are based on the direct measurement of the arc energy. However, in order to acquire the values of the desired quantities, a specialized measuring system is necessary. Furthermore, the measurement procedure is time-consuming.

An exemplary method is measuring arc radiation [25], or using a Rogowski coil [26]. A different approach to establishing arc energy is that based on measuring the heat transfer rate using a copper slug calorimeter sensor [27]. Bearing in mind the relatively complicated procedure for these methods, barring direct measurements of the arc energy, a combination of various methods is frequently applied. By registering indirect quantities, the $T_{a}$ and $\mathrm{E}_{\mathrm{a}}$ arc energy can be calculated, e.g., by discerning the duration of the arc burning time through spectral pyrometry [28] or extremely rapid camera capture [29].

The most popular and widely used approach for arc energy determination is a method based on simultaneous time-related voltage and current diagram registration [30-32]. The 
difference in the $T_{a}$ and $E_{a}$ calculation in this case lies in the various methods used for calculating the resultant quantities. As arc burning starting points and arc quenching points are indicated manually, the obtained results may be affected by errors. Similarly, because a large number of measurement files have to be analyzed within the framework of each experiment, the measurements may be time-consuming.

Bearing the aforementioned in mind, the switching capacity enhancement of LV circuit breakers was the main objective of the presented research. The main advantage of the presented method is the low cost of implementation. Moreover, the proposed idea does not require modifications of the original switch structure upon its application, as the additional system can be considered as being supplementary equipment.

In the research, experimental verification was executed and a detailed comparative analysis of the duration of the arc and a calculation of the arc energy volume generated during the switching-off process was carried out. Laboratory tests were performed on primary and on modified CB designs. Based on previously performed research results [33], an analysis of the observed relationship between the switching arc energy and arcing time duration current breaking capacity of the proposed solution was performed. In the evaluation, a method based on voltage and current diagram registration and its analysis with regard to switching arc energy was selected.

To speed up the analysis procedure in our study, a dedicated Matlab script was developed. The developed software can be used for the automatic processing of tests comprising unlimited amounts of data in practice.

\section{Idea Description}

Generally, each air-insulated LV CB consists of a continuously employed single main contact system. Therefore, these contacts have to be designed to take into account conditions of continuous operation, as well as the switching operation circumstances. Under continuous operation, main switching contacts are vulnerable to increased temperature as a result of the high current flow through the circuit. Therefore, the design and the materials used in the manufacturing of the contacts have to take into consideration operation under tough conditions. In practice, contacts must a provide low-voltage drop and must simultaneously secure protection against contact welding or contact burnout. The problem gains in importance in the case of short circuit current occurrences.

In the switching operation, rapid arc quenching and complete electric circuit interruption are required. Therefore, air-insulated current interrupters are additionally equipped with arc-quenching chambers. These increase the efficiency of the switching process. Such designs secure relatively effective current interruption. However, despite the application of the above-mentioned methods, unfavorable voltage and current surges and long switching arc duration result in contact degradation. As a consequence, the total switching capacity of CBs decreases. In extreme cases, an insufficient switching capacity may lead to connected circuit or installed CB failure.

A possible solution to these issues is to install CBs with high switching capacity, e.g., vacuum-insulated (VI) or $\mathrm{SF}_{6}$-insulated $\mathrm{CIs}$, but this entails drastically increased costs. Despite the many advantages of these types of CBs, the use of such efficient devices for $\mathrm{LV}$ power networks is economically unjustified. As a result, high efficiency $\mathrm{VI}$ and $\mathrm{SF}_{6}{ }^{-}$ insulated CBs are used mainly in MV and HV high-energy circuits. Bearing in mind the above, the ideal would be to combine the advantages of VI current interrupters with the low manufacturing costs of air-insulated LV CBs.

The proposition assumes the use of switching apparatus equipped with high-efficiency mechanical contacts S1 (Figure 1) in the main current path, thereby providing a lowvoltage drop and low-contact temperature (thus, greater contact durability) during normal operation. To ensure rapid arc quenching, S2 relay contacts dedicated for low-rated currents and placed under a vacuum or in a noble gas atmosphere are utilized. 


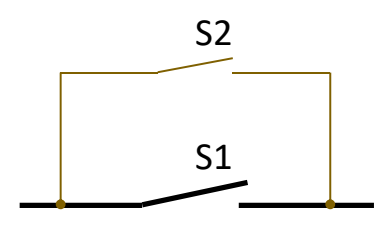

(a)

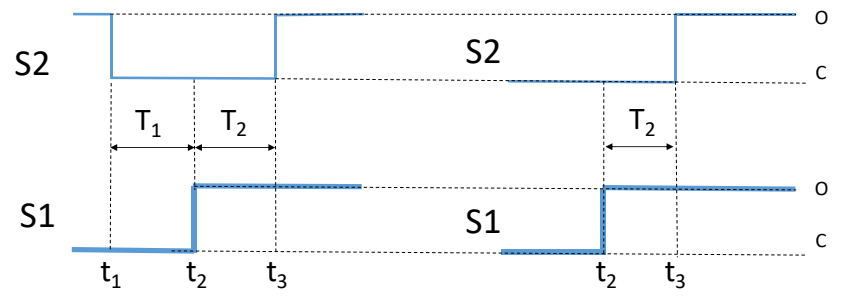

(b)

(c)

Figure 1. Combined low-voltage (LV) current interrupter principle of operation during switching operation: (a) main-S1 and arcing—S2 contact configuration; $(\mathbf{b}, \mathbf{c})$ contacts operating modes, $\mathrm{O} —$ contacts opened, $\mathrm{C}$-contacts closed.

The general principle of operation of the combined LV current interrupter is presented in in Figure 1.

Depending on the application, two possible operation modes are available:

1. At the continuous operation stage, arcing contacts remain opened so the load current flows through the main S1 current path (Figure 1b). Immediately before the commencement of the switching-off stage, arcing contacts S2 are closed at the $t_{1}$ moment. During the few milliseconds of $\mathrm{T}_{1}$ time, both contacts are closed. With regard to the arcing contacts, due to the significantly lower resistance of the main current path, the load current invariably flows through the main contacts. At the next stage, at the $t_{2}$ moment, the main contacts are opened. For the $T_{2}$ time duration, the current flows through the arcing contacts. At $t_{3}$, the arcing contacts are opened and the arc is quenched in the vacuum or noble gas environment.

2. In the second mode of operation (Figure 1c), for the duration of continuous operation, both contacts are closed; however, the main current flows through the main current path due to the lower resistance of the main contacts. At $t_{2}$, the main contacts are opened. Similarly to the first operation mode, during the $\mathrm{T}_{2}$ time duration, the current flows through the arcing contacts. At $t_{3}$, the arc quenching process initiation occurs at the VI contacts.

Both modes are very similar. The switching-off operation is realized via the VI insulated contacts. The main difference in operation occurs at the first stage, at the steady state and before the $t_{2}$ moment. Which operation will be finally selected depends on the particular CB construction and the control method applied. The main advantage of the first mode (b) is that, in using electromagnetic drive, energy for energizing the relay's coil is delivered during a short period only; thus, the drive coil is not subjected to overheating, and the volume of energy used for driving the coil is minimized. The weak point is a more complicated control procedure. The key condition to securing the appropriate mutual operation of the air-insulated main contacts and the arcing contacts is to secure suitable opening and closing at the specified moments. For experiment purposes, in order not to overload the components of the measuring stand, the first (b) operation mode was selected for all tests.

\section{Experimental Verification}

\subsection{Objects under Research}

We used MOELLER, ANIRO and EATON air-insulated LV electromagnetic contactors (EMCs) equipped with DC electromagnetic drives in this study, due to their general availability and low cost. A strategic reason for using such contactors in the main current path and reed relays as parallel circuits was that a suitable control method is relatively easy to implement.

Due to the specific principle of operation of the main switching apparatus, developing a supply control method had to take into account certain features [34]. The used CU needed to provide opening and closing S1 and S2 contacts at specified moments, thus energizing and de-energizing the driving coils had to be realized at certain times. 
In the case of the contactors, the mass of the movable armature coupled with the contacts affects the armature movement delay $\left(\mathrm{T}_{0}\right)$, this being the time between the moment of supply voltage application $t\left(U_{s}\right)$ and the moment of movement start $t_{m}$. In view of the movement duration $\left(\mathrm{T}_{\mathrm{m}}\right)$, the final switching time $\left(\mathrm{T}_{\mathrm{s}}\right)$ is generally described as in Equation (1), where $T_{S}$ defines the time required for the achievement of switching processes $\left(t_{s}\right)$ (Figure 2):

$$
\mathrm{T}_{\mathrm{s}}=\mathrm{T}_{0}+\mathrm{T}_{\mathrm{m}}
$$

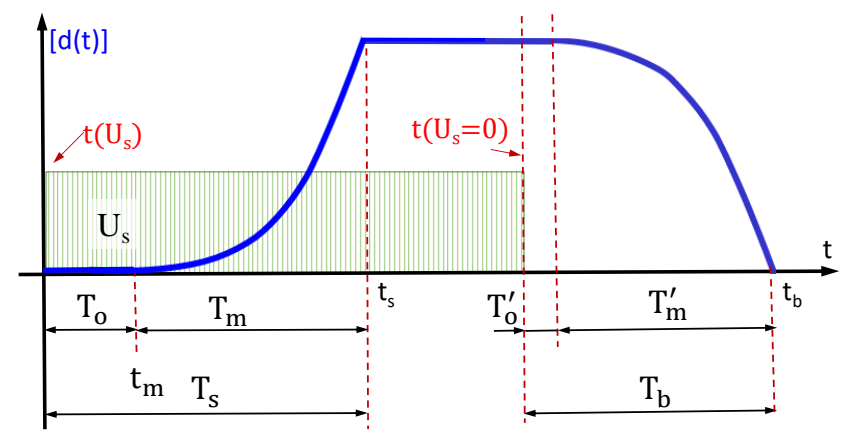

Figure 2. DC electromagnet actuated $C B$ operating procedure: $d(t)$-armature movement path, $\mathrm{T}_{\mathrm{o}}$-movement delay; $\mathrm{T}_{\mathrm{m}}$-movement duration; $\mathrm{T}_{\mathrm{s}}$ - switching time; $\mathrm{T}^{\prime}{ }_{\mathrm{o}}$-movement delay during breaking; $\mathrm{T}_{\mathrm{m}}^{\prime}$-movement duration during breaking; $\mathrm{T}_{\mathrm{b}}$ - breaking time; $\mathrm{t}_{\mathrm{s}}$ - contacts making moment; $t_{b}$ - contacts breaking moment; $U_{s}$ —supply source; $t\left(U_{s}\right)$ - supply source delivery moment; $\mathrm{t}\left(\mathrm{U}_{\mathrm{s}}=0\right)$ - supply source disconnection moment.

Reed relay switching apparatuses are devoid of movable armature and the contacts are characterized by negligible mass. However, despite this and because of the time required for driving coil energization, a similar relationship is applicable. In our study, the EMC coil energization time was neglected due to its relatively small value in comparison to the $\mathrm{T}_{0}$ and $\mathrm{T}_{\mathrm{m}}$ values generated by means of armature movement inertia. In addition, $\mathrm{a}$ comparable relationship is noticed in the case of breaking operation and breaking time $\left(T_{b}\right)$. Herein, in selecting the appropriate moments for connecting $t\left(U_{s}\right)$ and disconnecting $t\left(U_{s}=0\right)$, the power supply to the electromagnet's driving coils determines the ability of the switching apparatuses to achieve the desired switching cycle.

The problem gains in importance in the case of a change in the operation conditions, e.g., driving electromagnet parameter changes, resistive forces variability or gravity forces direction. The only electromagnetically actuated devices that can be assumed to secure the elementary condition (relative stability of the operating parameters) were switching apparatuses equipped with DC electromagnetic drives.

$\mathrm{CU}$ calibration and the selection of the coil energization and de-energization moments had to be performed after installing the contactors in the target operation position. For experimental purposes, a horizontal operation position was selected, as this the most commonly utilized form. In this position, the movable armature moves repositions in a horizontal direction.

Another specific feature of all CBs equipped with classic, mechanical contacts is the contact-bouncing effect that takes place during the switching-on operation.

In our experiment, the contact-bouncing time durations $\left(\mathrm{T}_{\mathrm{cb}}\right)$ for each of the used switches were additionally measured. Using a circuit composed of a DC voltage source and resistors connected in series with the switch's contacts, the $\mathrm{T}_{\mathrm{s}}, \mathrm{T}_{\mathrm{b}}$ and contact-bouncing effect registration was feasible by registering the voltage drop at the contacts.

Here, $T_{s}$, the time duration from the moment of energizing the driving coil $t\left(U_{s}\right)$ to the contacts closing moment, was recognized by means of registering the zero-voltage drop level $\mathrm{u}_{\mathrm{c}}(\mathrm{t})$ occurrence at the contacts (Equation (2)). The $\mathrm{T}_{\mathrm{b}}$, time duration between the 
coil's supplying voltage disconnection moment and the moment of voltage drop $\mathrm{u}_{\mathrm{c}}(\mathrm{t})$ at the contacts appearance, is determined using Equation (3):

$$
\begin{gathered}
T_{s}=t\left(u_{c}(t)=0\right)-t\left(U_{s}\right) \\
T_{b}=t\left(u_{c}\right)-t\left(U_{s}=0\right)
\end{gathered}
$$

where: $t\left(u_{c}(t)=0\right)$ is the contact closing moment; $t\left(U_{s}\right)$ is the moment of the supply voltage application; $t\left(u_{c}\right)$ is the contact separation moment; and $t\left(U_{s}=0\right)$ is the supply voltage disconnection moment.

Using the same procedure, the contact-bouncing effect was also recognized. Depending on the switch construction, the time extent of the contact-bouncing may even be dozen of milliseconds. The duration of the effect mainly depends on the switching apparatus design, movement speed and load current value. To properly execute the procedure for opening and closing the main and arcing contacts, this effect should be taken into account during CU operation programming. Suitable contact closing and opening moments should be realized after the transient state of the contacts of the connected in parallel cooperating switch has been completed.

In fact, during our experiments, according the first operation mode (Figure 1b), in order not to overload the measuring system, the contactor's contacts were closed a short time before the main switching-off operation began at $t_{0}$ (Figure 3 ). This was usually realized approximately $1-2$ s before the target switching-off operation was executed. During normal operation, this stage is omitted and the contacts are closed.

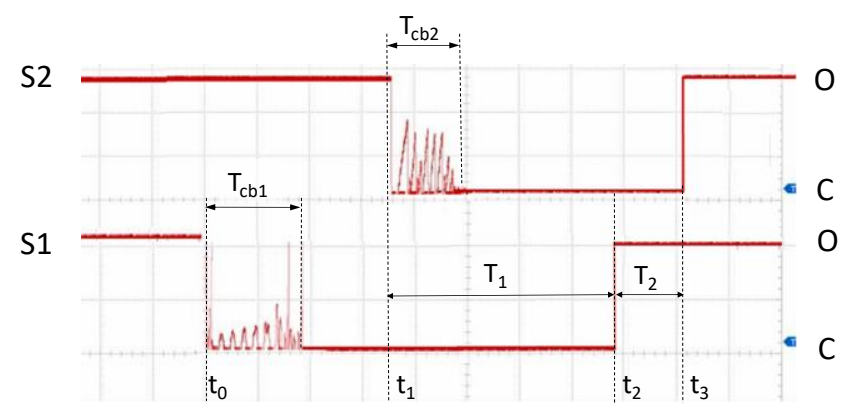

Figure 3. Exemplary recorded transient states of the contactors and relay contacts: S1-air-insulated $\mathrm{CB}$; $\mathrm{S} 2$ - vacuum-insulated relay; $\mathrm{T}_{\mathrm{cb} 1}$ - contactors' contact-bouncing time; $\mathrm{T}_{\mathrm{cb} 2}$-relays' contactbouncing time; $\mathrm{O}$-contacts opened; $\mathrm{C}$-contacts closed.

In the course of our experiment, we found that the relay's arcing contacts were closed at $t_{1}$ after the transient state $\mathrm{T}_{\mathrm{cb} 1}$ of the contactor $\mathrm{S} 1$ had finished. Similarly, in case of the contactors' contacts, the assumption was to open the contactors' contacts at $t_{2}$, when the transient state $\mathrm{T}_{\mathrm{cb} 2}$ of the relay's contacts was terminated.

The main criterion for selecting contactors for the experiments was their rated current $I_{n}$ values. Bearing in mind that the apparatuses we experimented with were intended for breaking similar rated currents, we intended to evaluate their switching $\left(T_{s}\right)$ and breaking $\left(\mathrm{T}_{\mathrm{b}}\right)$ times and duration repeatability. These parameters had to be manually measured to secure the realization of the switching-off operation according to Figure 1.

Commonly available low-cost reed relays are characterized by holding relatively lowrated current (usually $3 \mathrm{~A}$ ) values. In turn, the dielectric withstanding between the contacts for all relays is high, which comes about due to the effect of vacuum insulation application.

As with the contactors, in view of the needs of the experiment, the selected parameters of the particular relays had to be experimentally verified. The purpose of employing this type of device for the presented idea was to examine the possibility of using vacuum relays with high dielectric strength and a low-rated continuous rated current for breaking the higher currents. A key condition to meeting this assumption was to realize the switching- 
off operation during a short period. We assumed that VI current interrupter usage would provide limitations on the switching arc, hence affecting rapid contact degradation.

Tables 1 and 2 show the basic rated parameters of the tested switching apparatuses (contactors and relays), as well as the measured average values of switching times $\mathrm{T}_{\mathrm{s}}$, breaking times $\mathrm{T}_{\mathrm{b}}$ and contact-bouncing time durations $\mathrm{T}_{\mathrm{cb}}$.

Table 1. Basic parameters of tested contactors.

\begin{tabular}{ccccccc}
\hline Sample & $\mathbf{U}_{\mathbf{n}}[\mathbf{V}]$ & $\mathbf{I}_{\mathbf{n}}[\mathbf{A}]_{(\mathbf{A C}-3)}$ & $\mathbf{U}_{\mathbf{s}}[\mathbf{V}]$ & $\mathbf{T}_{\mathbf{s}}[\mathbf{m s}]$ & $\mathbf{T}_{\mathbf{b}}[\mathbf{m s}]$ & $\mathbf{T}_{\mathbf{c b}}[\mathbf{m s}]$ \\
\hline CB1 & 400 & 16 & 24 & $30.53^{*}$ & $31.00^{*}$ & $0.69 *$ \\
CB2 & 400 & 17 & 24 & $44.52 *$ & $28.55 *$ & $0.72 *$ \\
\hline${ }^{*}$ measured; $\mathrm{U}_{\mathrm{s}}$-driving coil voltage.
\end{tabular}

Table 2. Parameters of tested reed relays.

\begin{tabular}{ccccccccc}
\hline Sample & $\begin{array}{c}\mathbf{U}_{\max } \\
{[\mathbf{k V}]}\end{array}$ & $\mathbf{I}_{\mathbf{n}}[\mathbf{A}]$ & $\mathbf{U}_{\mathbf{s}}[\mathbf{V}]$ & $\begin{array}{c}\mathbf{R}_{\mathbf{c}} \\
{[\mathbf{m} \Omega]}\end{array}$ & $\begin{array}{c}\mathbf{R}_{\mathbf{i}} \\
{[\mathbf{G} \boldsymbol{\Omega}]}\end{array}$ & $\mathbf{T}_{\mathbf{s}}[\mathbf{m s}]$ & $\mathbf{T}_{\mathbf{b}}[\mathbf{m s}]$ & $\begin{array}{c}\mathbf{T}_{\mathbf{c b}} \\
{[\mathbf{m s}]}\end{array}$ \\
\hline $\mathrm{R} 1$ & 7 & 2 & 24 & 250 & 1000 & 2 & 3 & $0.82^{*}$ \\
$\mathrm{R} 2$ & 7.5 & 5 & 24 & 150 & 1000 & 3.2 & 1.5 & $0.68^{*}$ \\
\hline
\end{tabular}

$\mathrm{U}_{\max }$-dielectric withstand; $\mathrm{I}_{\mathrm{n}}$-rated current; $\mathrm{U}_{\mathrm{s}}$-driving coil voltage; $\mathrm{R}_{\mathrm{c}}$-contacts' resistance; $\mathrm{R}_{\mathrm{i}}$-insulation resistance; * measured.

For comparison, contactors dedicated for various operation categories (AC1 vs. AC3) were selected and characterized by various rated switching capacities. In the experiment, a CB1 contactor was used for assessing resistive load current interruption (AC1), and a CB2 contactor was employed for discerning inductive loads (AC3).

For statistical reasons and in order to limit the impact of the manufacturing inaccuracies of each of the tested pieces, measurements were obtained for two examples of each contactor. For the testing, we selected two items from among five reed relay switches. The selected devices were characterized by having the lowest variation of measured $T_{s}, T_{b}$ and $\mathrm{T}_{\mathrm{cb}}$ parameters. As later observed, the assumed endurance of the tested reed relays was sufficient for the experimentation, and long-term testing did not confirm any failures noticed during the scope of testing.

\subsection{Control Unit and Test Stand Description}

For the purpose of the experiment, a dedicated control unit (CU) was developed. This $\mathrm{CU}$ was responsible for the appropriate energization procedure realization of the driving coils of air- and vacuum-insulated switching apparatuses. The elaborated control unit was based on an Arduino UNO module with an implemented Atmega 328 microcontroller. The controller allows for cyclical switching-on and switching-off of the connected-in switching devices by means of two solid-state relays (SSR1 and SSR2 in Figure 4) responsible for energization and supply disconnection at the specified moments. In using the employed solid-state relays, the CU allowed for a precise set of energization procedures with an accuracy of approximately $0.2 \mathrm{~ms}$. Taking into account the determined switching times $\left(\mathrm{T}_{\mathrm{s}}\right)$ and breaking times $\left(\mathrm{T}_{\mathrm{b}}\right)$ of the used CIs, the achieved switching accuracy was considered suitable for the needs of the experiment. In the course of the tests, both previously presented operation modes (Figure 1) were examined.

The CU was then incorporated into the measurement stand. This consisted of the control unit, the tested CBs (S1) and relays (S2) and inductive load (R-L Load), as well as a digital oscilloscope (Figure 4). For the AC current measurements, a standard current probe was used. The DC current measurements were realized through the $0.1 \Omega$ reference resistor $\left(R_{r}\right)$ and a dedicated voltage probe (VPC). The same control unit was employed during the entire experiment; however, for each tested EMC and reed relay, switch calibration had to be performed, and the $\mathrm{T}_{1}$ and $\mathrm{T}_{2}$ times had to be set for each contactor-relay configuration.

This was forced by the differences in switching and breaking time values for each copy of the tested CI. In order to verify the effectiveness of the idea, large-scale laboratory 
experiments were executed by employing the test stand in the configurations shown in Figures 4 and 5.

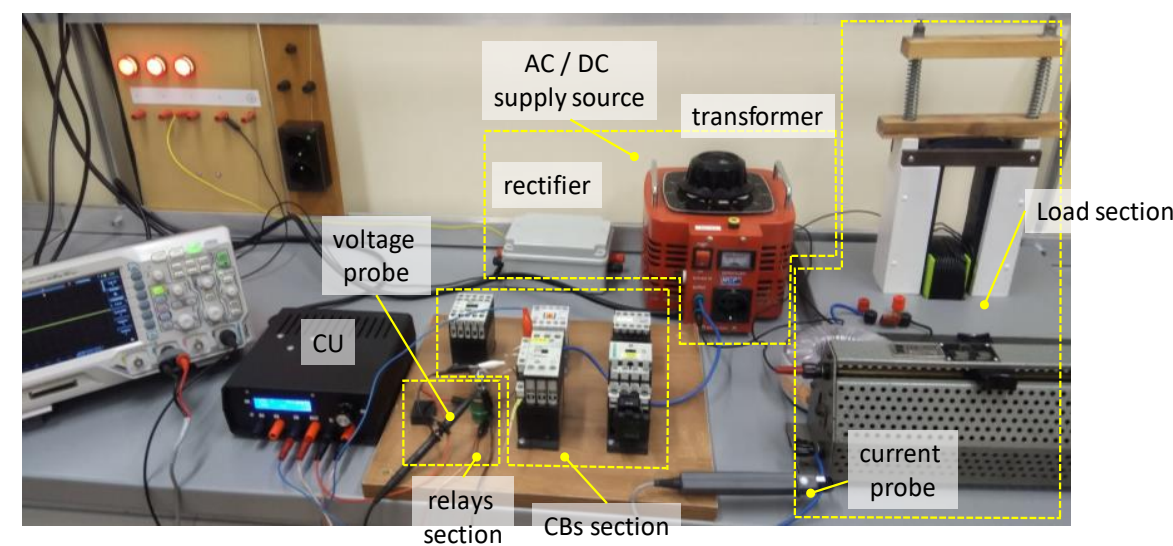

Figure 4. Test stand general view.

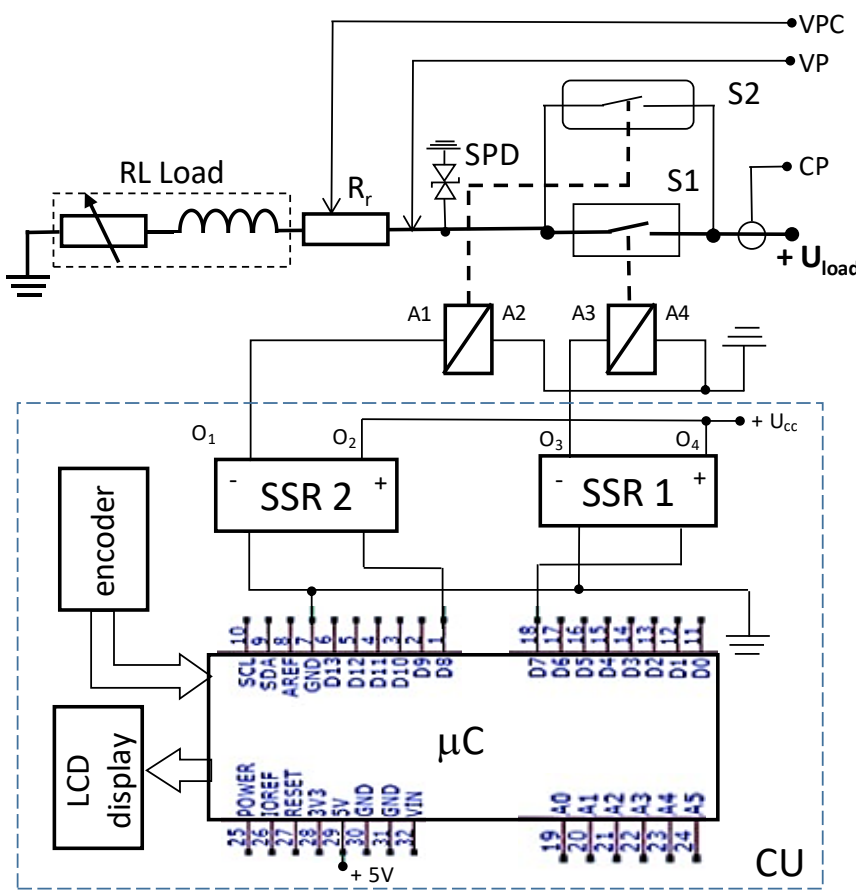

(a)

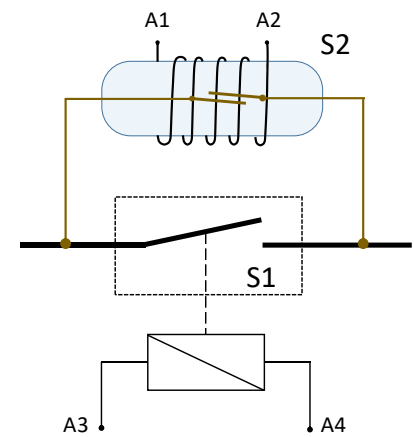

(b)

Figure 5. (a) Diagram of the test stand: $\mathrm{CU}$-control-unit, $\mu \mathrm{C}$-microcontroller, SSR1/SSR2—solid-state relays, $\mathrm{O}_{1}-\mathrm{O}_{4}-$ control unit terminals, A1-A4-contactor and relay driving coil terminals, S1—air-insulated switch, S2—vacuum-insulated switch, $\mathrm{U}_{\mathrm{cc}}$ —control unit supply source, SPD—surge protective device, $\mathrm{R}_{\mathrm{r}}$-reference resistor, VP—voltage probe, VPC— voltage probe for DC current measurement, $\mathrm{CP}$-current probe, $\mathrm{U}_{\text {load }}$-load circuit supply source; (b) practical realization of the air-vacuum combined switch.

\subsection{Measurement Procedure and Data Post-Processing}

The main stage of the experiment comprised the measurement of the parameters of the switching arc generated during the current breaking operation. For this purpose, a frequently used method based on the simultaneous registration of voltage and current signal waveforms was employed. The relevant data were obtained by means of digital oscilloscope with an implemented function of automatic storage of the recorded waveforms. 
The resulting data were stored in the form of *.csv output files containing calculated data records and ${ }^{*}$.jpg graphic files.

Tests were executed on the inductive load, being the most frequently found load type. The value of the parameters of the inductive load was necessitated by the need to meet the international standards that establish the maximum value of reactive power allowed for municipal and industrial customers [35]. The load utilized for the tests contained an air coil and a combination of the wirewound variable resistors $(R=42 \Omega)$ and inductive elements $\left(\mathrm{L}=57 \mathrm{mH}, \mathrm{X}_{\mathrm{L}}=6.3 \Omega, \cos \varphi=0.92\right)$ connected in series.

The main tests were carried out on the AC and DC 5 A RMS value of load current and contactors rated voltage $(230 \mathrm{~V})$. The assumed experiment parameters were dictated by the maximum rated current of the utilized reed relays.

Tests were executed on two stages:

1. Tests on the air-insulated electromagnetic contactors used as a single current interrupter for the inductively loaded circuit;

2. Tests on air-insulated EMCs coupled with a vacuum reed relay switches acting as arcing contacts.

For each individual test, the voltage-current waveforms were recorded. Based on these data, the arcing times $\left(\mathrm{T}_{\mathrm{a}}\right)$ were calculated.

Before the target measurements were calculated, a preliminary calibration procedure was performed in view of the tested CIs' parameter determination. As part of the preliminary tests, 100 measurements of the $T_{s}, T_{b}$ and $T_{c b}$ time durations were determined on each CI. An average value of the obtained data was subsequently calculated, the results of which are listed in Tables 1 and 2. The achieved coefficient of variability of the measured values was relatively low $(\leq 2 \%)$ and allowed for a determination of the switching parameters at the experiment's next stage. For this purpose, the $T_{1}$ and $T_{2}$ parameters were assumed according to the data listed in Table 3 . The assumed values were dictated by the minimum values of the transient state duration presence of the CIs.

Table 3. Switching procedure of S1 (air-insulated) and S2 (vacuum-insulated) relays.

\begin{tabular}{cc}
\hline $\left.\mathbf{T}_{1} \mathbf{[ m s}\right]$ & $\left.\mathbf{T}_{\mathbf{2}} \mathbf{[ m s}\right]$ \\
\hline 1 & 1 \\
2 & 2 \\
2 & 1 \\
\hline
\end{tabular}

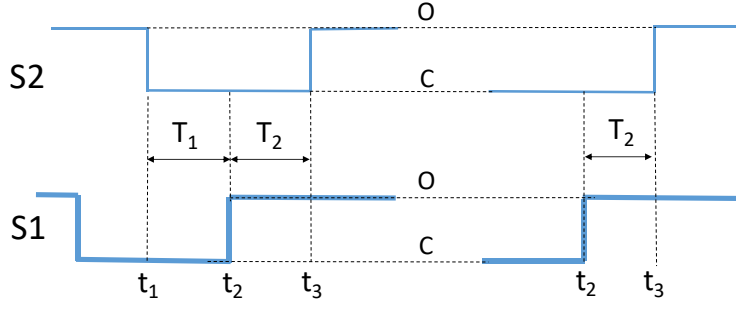

(a)

(b)

C—contacts closed; O—contacts opened; S1—air-insulated current interrupter; S2—vacuum-insulated relay; $(\mathbf{a}, \mathbf{b})$ - contacts operating modes.

Finally, the data obtained by means of oscilloscopic measurement were analyzed in view of the parameters of the switching arc generated during the current-breaking operation. The voltage and current recorded waveforms were analyzed in respect of arc time duration and the ensuing arc energy generated during switching-off operation.

The test comprised 100 switching-off operations realized in two stages:

1. For each contactor operating as a single air-insulated current interrupter;

2. For each "contactor -relay" configuration.

Based on the recorded diagrams, the final desired quantities were calculated for each of the executed current breaking operations:

- $\quad$ Arcing time $\left(\mathrm{T}_{\mathrm{a}}\right)$;

- Arc energy $\left(\mathrm{E}_{\mathrm{a}}\right)$;

- Level of voltage surges occurring during current breaking $\left(\mathrm{U}_{\mathrm{sg}}\right)$ (if these occurred). 
The study required a detailed analysis of a large number of recorded diagrams obtained in the framework of the experiments. In view of the large amount of collected data, for the purpose of the research, dedicated software was developed. In order to make a comprehensive range of analysis and for analysis process automation, a dedicated software tool was developed through Matlab script.

The switching arc registration and calculation of its parameters were carried out automatically using the developed script. For recorded data post-processing needs, each of the recorded waveforms was divided into three time intervals (Figure 6): 1-voltage drop at the closed contacts assumed as a voltage noise signal being the result of contact resistance; 2-arcing time; and 3-voltage at the opened contacts, including oscillations at the inductively loaded circuit. Meanwhile, four moments were specified: $t_{1}$-beginning of the registration; $t_{2}$-arc burning starting moment; $t_{3}$-arc quenching moment; and $\mathrm{t}_{4}$-registration finishing point.

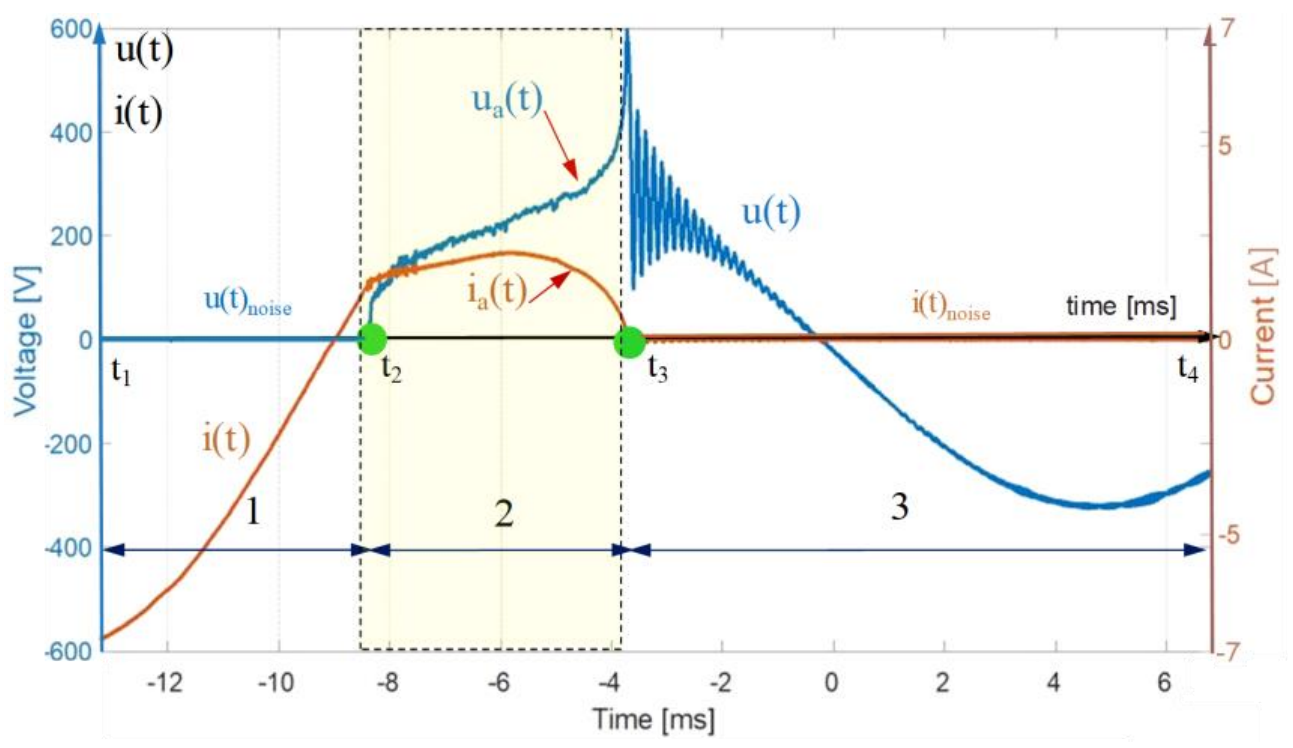

Figure 6. Exemplary recorded waveforms of AC load current and voltage across the contacts registered during air-insulated EMC's contact breaking: $\mathrm{u}_{\mathrm{a}}(\mathrm{t})$ —arc voltage; $\mathrm{i}_{\mathrm{a}}(\mathrm{t})$ —arc current.

To determine the arc burning starting point, the voltage across the contacts was monitored. Due to the resistance of the contacts, the presence of a small voltage drop at the contacts of the EMCs and the reed relay switches was observed. The impact of the problem increased for the relatively higher current values. The voltage drop at the closed contacts was assumed to be noise signal $\left(\mathrm{u}(\mathrm{t})_{\text {noise }}\right)$. According to Figure 6, the first sample with a recorded voltage drop higher than the assumed noise signal recorded between the $t_{1}$ and $t_{2}$ moments is considered as the arc burning starting point. Similarly, the time of arc burning finish was determined as the point on the diagram of the current where the signal $i(t)$ value equals the noise maximum value $i(t)_{\text {noise }}$ recorded between the $t_{3}$ and $t_{4}$ moments.

The elaborated software (Figure 7) automatically implemented an extraction of the resultant data from the obtained measurements. It then calculated the necessary quantities and generated an output file. The Matlab script used as input data, ${ }^{*}$.csv files obtained from oscilloscope readings that contained recorded voltage and current time-related waveforms in numerical form. 


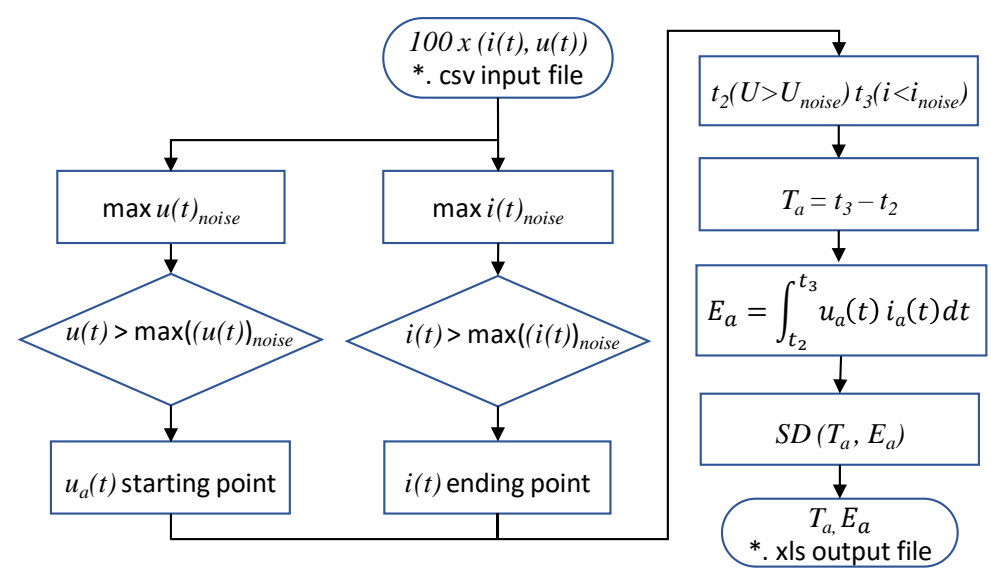

Figure 7. Software operation diagram: $T_{a}$-arcing time between the $t_{2}$ and $t_{3}$ moments; $E_{a}$-arc energy between the $t_{2}$ and $t_{3}$ moments; $\max u(t)_{\text {noise, }}$ max $i(t)_{\text {noise }}$-maximum values of voltage and current noise signal; $\mathrm{u}_{\mathrm{a}}(\mathrm{t}), \mathrm{i}_{\mathrm{a}}(\mathrm{t})$-voltage and current time-related arc parameters.

The final output files were in the form of *xls files and held arcing time $\left(T_{a}\right)$, and the average values and standard deviation (SD) as calculated for each of the calculated quantities of the recorded measurements.

The arcing time $\left(T_{a}\right)$ was calculated as a result of a subtraction between $t_{3}$ and $t_{2}$ moments (Equation (4)) representing the arc quenching moment and the arc burning starting moment:

$$
\mathrm{T}_{\mathrm{a}}=\mathrm{t}_{3}-\mathrm{t}_{2}
$$

The arc burning starting and ending points determined the arc energy by using Equation (5):

$$
E_{a}=\int_{t_{2}}^{t_{3}} u_{a}(t) \cdot i_{a}(t) d t
$$

Due to the large number of performed measurements, the obtained results were analyzed statistically. The statistical procedure contained the average values and standard deviation (SD) of the calculated data.

\subsection{Measurements Results}

Figure 8 presents the recorded exemplary voltage waveforms across the contacts of the air-insulated current interrupters $(a, b)$ and, for comparison, the voltage across the vacuum-insulated contacts $(c, d)$ of the reed relay switches.

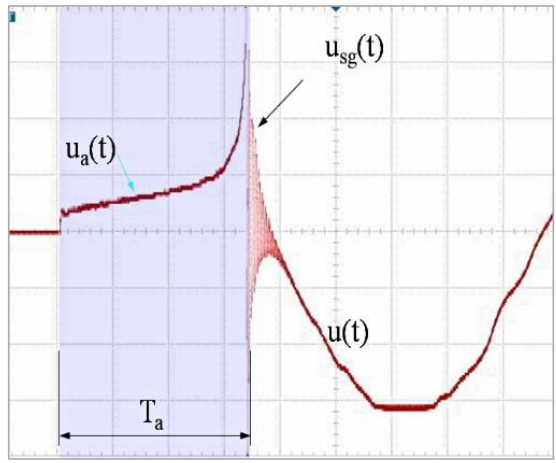

(a)

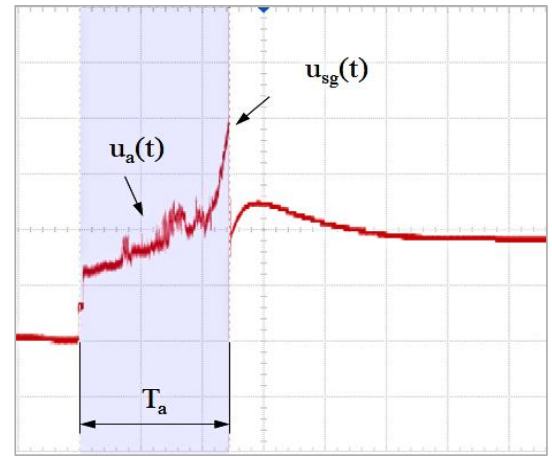

(b)

Figure 8. Cont. 


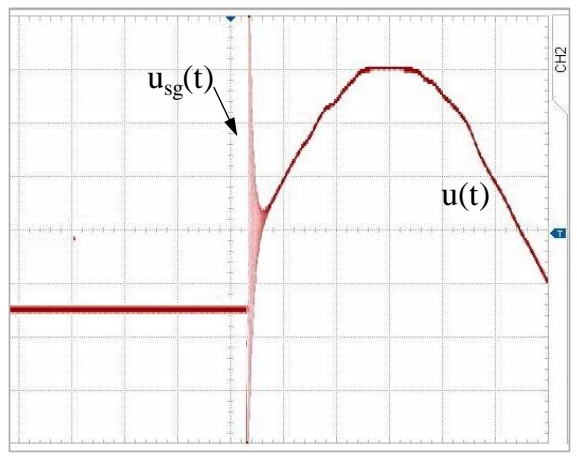

(c)

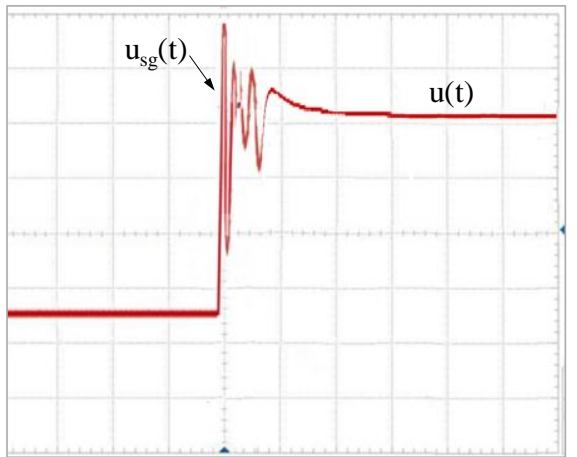

(d)

Figure 8. Voltage waveforms recorded for $(\mathbf{a}, \mathbf{b})$ air-insulated contactors and $(\mathbf{c}, \mathbf{d})$ vacuum-insulated arcing contacts of reed relay switches: $\mathrm{u}(\mathrm{t})$ - voltage across the contacts; $\mathrm{u}_{\mathrm{a}}(\mathrm{t})$ - $\operatorname{arc}$ voltage; $\mathrm{u}_{\mathrm{sg}}(\mathrm{t})$ voltage surge.

The experimental results indicate the essential increase of the switching capacity enhancement of the combined switching circuit, in comparison with that of the single, air-insulated circuit breaker. In the case of the air-insulated current interrupters in the form of electromagnetic contactors, noticeable arc burning times $\left(T_{a}\right)$ were recorded. VI contact implementation allowed arcing time reduction or switching arc elimination (as revealed in Figure 8c,d).

The weak points of the method are the observed higher amplitude and frequency voltage surges $U_{s g}(t)$ indicated during current breaking. This phenomenon, while typical for VI CBs, can be limited by means of applying an appropriate surge protective device (SPD). Moreover, the AC3 operating category contactors were able to break the load current noticeably faster, in comparison with the AC1 category contactors. This is a normal phenomenon, being the result of the different switching capacities of the contactors and the applied arc quenching system designs.

As expected, the average value of the recorded $\mathrm{T}_{\mathrm{a}}$ time duration was approximately $5 \mathrm{~ms}$ for the air-insulated contactors and AC current (Figure 9a). This resulted from the application of air insulation between the contactor contacts and the dielectric strength of the air insulation. For low-current values, the recorded $T_{a}$ times were within range of few milliseconds (usually $<5 \mathrm{~ms}$ ). For the higher AC current values, the duration of the arc burning was longer. Usually, the recorded waveforms indicated arc quenching moment $t_{3}$ at the falling edge of the current waveform.

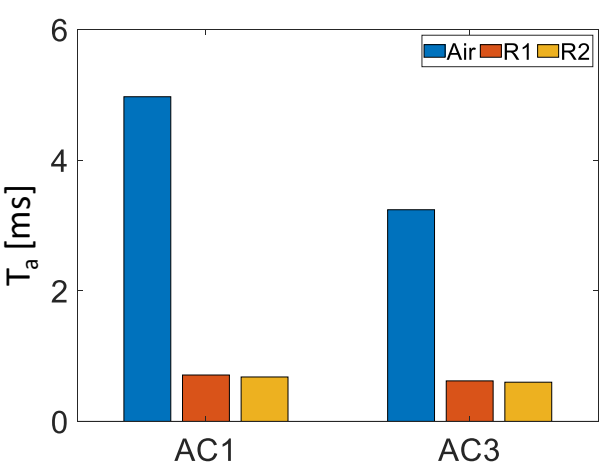

(a)

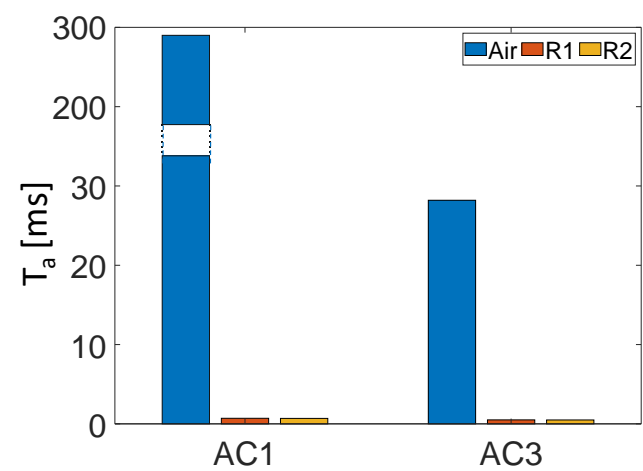

(b)

Figure 9. Average values of arc burning times $T_{a}$ for various $C B$ operation categories: (a) $A C$ current interruption, (b) DC current interruption: R1, R2 - results for R1 and R2 type of reed relay switching apparatus, respectively; Air-air-insulated CB. 
The additional VI arcing contacts application in the form of reed relay switches affected the arc burning time reduction. The VI switching apparatus application allowed for some reduction of the arcing time duration. Furthermore, normally, the observed arc duration was lower than $0.5 \mathrm{~ms}$, and most often, a complete arc elimination was noticed.

The interruption of a DC current in the air entailed a significant increase in arcing time duration. In extreme cases, the observed arc burning times were at the level of several dozen, or even several hundred, milliseconds (Figure 9b). In contrast, the reed relay switch applications operating as the arcing contacts reduced the switching arc times to several milliseconds only. Similarly to AC current interruption, the most often recorded arc duration was within the range of $0.5 \mathrm{~ms}-1 \mathrm{~ms}$.

Variations in the arc burning times resulted in differences in the values of arc energy during current interruption (Figure 10). The average value of the energy of the arc $\mathrm{E}_{\mathrm{a}}$ generated in the case of AC current interruption (Figure 10a) between VI arcing contacts was approximately 6-7 times smaller than that in the case of the arc occurring between the air-insulated contacts.

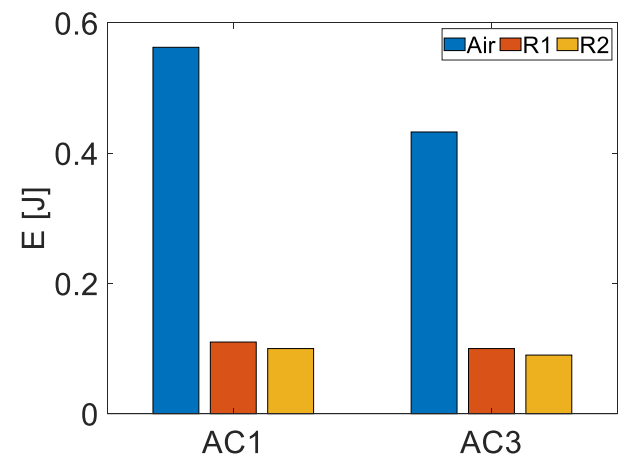

(a)

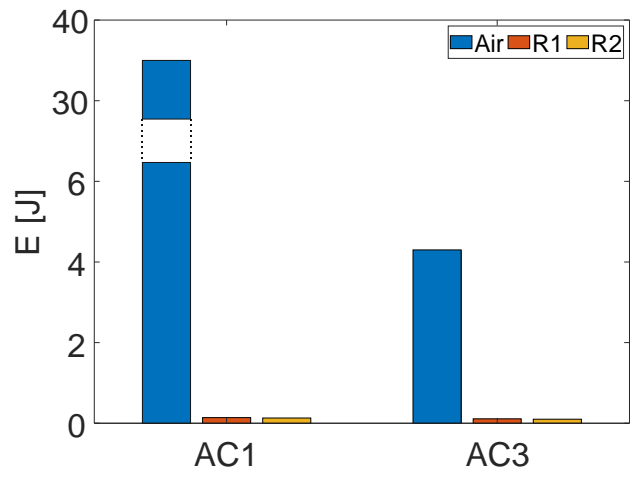

(b)

Figure 10. Average values of arc energy $E_{a}$ for various $C B$ operation categories: (a) AC current interruption, (b) DC current interruption; R1, R2-results for R1 and R2 types of reed relay switching apparatus, respectively; Air-results for air-insulated CB.

DC current interruption in the VI arcing contacts resulted in approximately a 100 times reduction of the switching arc energy (Figure $10 \mathrm{~b}$ ).

The supplementary objective of the tests was to check the applicability of the designed circuit equipped with vacuum reed relays dedicated for low-rated currents for breaking the higher currents. Assuming the utilization of the arcing contacts only for breaking the switching arc, in the framework of the experiment, an estimation of the durability of such a structure for this specific application was performed. For this purpose, tests for 20 A of load current value were executed.

The measurement results revealed the potential applicability of such a switch design for breaking the currents with values higher than reed relay-rated current values. In the framework of the tests, 100 measurements were executed. The obtained results indicated similar values for the recorded arcing times as for the case of $5 \mathrm{~A}$ of load current. The average $\mathrm{T}_{\mathrm{a}}$ value was at the $1.5 \mathrm{~ms}$ level; however, an arc-less switching-off operation was very rarely observed. No failures of the reed relay switches were noticed at the end of the tests. Similarly, no reduction in the switching capacity of the VI relays was observed. At the beginning and at the end of the tests recorded, the $\mathrm{T}_{\mathrm{a}}$ times had comparable values.

During the application of VI switches to break the load current, higher voltage surge levels and a higher occurrence frequency was observed in comparison with the air-insulated CBs. Moreover, the oscillations that occurred after breaking the current were characterized by higher frequency. The maximum value of the recorded voltage surges $\left(u_{\mathrm{sg}}\right)$ was at $1.1 \mathrm{kV}$. Therefore, most of the tests were realized using a SPD for the protection of the equipment. 


\section{Summary}

As a result of experimentation involving the introduced modifications, the enhanced effectiveness of the current breaking of the tested CIs was achieved. The positive results of the verification experiments were observed for various types of tested switching apparatuses.

In comparison to the basic design of CIs equipped with single contacts systems, the provision of additional arcing contacts dedicated for operation during the current breaking process allowed for a reduction in the duration of the switching-off process. Similar results were observed for both AC and DC current interruption. For the original designs, arc burning times were at the level of several dozen, or even several hundred, milliseconds. The achieved reduction of the arcing time, and thus the limitation of the switching arc energy for interrupting the AC currents, was at the level of approximately 5-6 times. In contrast to the original switch design, the reed relay switch applications operating as arcing contacts reduced the switching arc times to only several milliseconds. Most frequently, the arc duration was shorter than $1 \mathrm{~ms}$ or complete arc elimination was achieved. This resulted in a several times reduction of the arc energy (approximately 6-7 times).

The increased current breaking effectiveness was particularly noticeable for the DC current interruption of the inductively loaded circuit. In this case, a several hundred times shorter duration of arc burning time was indicated. The resulting arc energy that dissipated during the DC breaking operation was reduced several dozen times.

Breaking currents by means of air-insulated CIs intended for operation under the AC1 operation category, as expected, brought about a significant elongation of the switching arc duration in comparison with CIs operating under the AC3 category.

By incorporating an additional VI arcing contact, the problem of using CIs that normally operate at a lower operation category for breaking inductively loaded circuits was solved.

Here, the air-insulated switching apparatus conducted current only during a steady state. The switching-off process was realized by means of an additional VI contact system.

The tests results indicated that in the application of the presented method, the addition of an SPD is recommended due to the occurrence of voltage surges.

Author Contributions: Conceptualization, D.S. and M.B.; methodology, D.S and M.B.; software, M.B.; validation, D.S., M.B.; formal analysis, D.S.; investigation, D.S.; resources, D.S.; data curation, M.B.; writing—original draft preparation, D.S.; writing—review and editing, D.S.; visualization, D.S. and M.B.; supervision, D.S.; project administration, D.S.; funding acquisition, D.S. All authors have read and agreed to the published version of the manuscript.

Funding: This research received no external funding.

Institutional Review Board Statement: Not applicable.

Informed Consent Statement: Not applicable.

Data Availability Statement: Data available on request due to restrictions eg privacy or ethical.

Conflicts of Interest: The authors declare no conflict of interest.

\section{References}

1. Wu, Z.; Wu, G.; Chen, C.; Fang, Y.; Pan, L.; Huang, H. A novel breaking strategy for electrical endurance extension of electromagnetic alternating current contactors. IEEE Trans. Compon. Packag. Manuf. Technol. 2016, 6, 749-756. [CrossRef]

2. Valentine, R.D. A Perspective of Low-Voltage Circuit Breaker Interrupting Rating. IEEE Trans. Ind. Appl. 2000, 36, 916-919. [CrossRef]

3. Derevyankin, P.G.; Frolov, V.Y.; Kriskovets, D.S.; Yushin, B.A. Analysis of the Electrophysical and Thermophysical Properties of Copper-Graphite Material for Arcing Contacts of a High-Current Low-Voltage Circuit Breaker. In Proceedings of the 2021 IEEE Conference of Russian Young Researchers in Electrical and Electronic Engineering (ElConRus), St. Peterburg, Moscow, Russia, 26-29 January 2021.

4. Mützel, T.; Niederreuther, R. Development of Contact Material Solutions for Low-Voltage Circuit Breaker Applications. In Proceedings of the 2011 IEEE 57th Holm Conference on Electrical Contacts (Holm 2011), Minneapolis, MN, USA, 11-14 September 2011. 
5. Honmat, H.; Kimura, S.; Shoji, K.; Wakatsuki, N. Arc discharge and surge suppression during a breaking operation of a magnetic relay. In Proceedings of the 53rd IEEE HOLM Conference on Electrical Contacts, Pittsburgh, PA, USA, 16-19 September 2007; pp. 280-283.

6. Cai, Z.; Gong, H.; Ma, S. Analysis and improve of electromagnet mechanism for integrated control and protective switching devices. In Proceedings of the 2008 International Conference on Electrical Machines and Systems (ICEMS), Wuhan, China, 17-20 October 2008; pp. 4277-4280.

7. Fazel, M.; Gholam-Abbas, N.; Saif, M. A New Topology of a Fast Proactive Hybrid DC Circuit Breaker for MT-HVDC Grids. Sustainability 2019, 11, 4493.

8. Niehoff, R. Circuit Breaker with Hybrid Switch. U.S. Patent US9947496B2, 17 April 2018.

9. Xu, C.; Damle, T.; Graber, L. A Survey on Mechanical Switches for Hybrid Circuit Breakers. In Proceedings of the 2019 IEEE Power \& Energy Society General Meeting, Atlanta, GA, USA, 4-8 August 2019.

10. Swingler, J.; McBride, J.W. Micro-Arcing and Arc Erosion Minimization Using a DC Hybrid Switching Device. IEEE Trans. Compon. Packag. Technol. 2008, 31, 425-430. [CrossRef]

11. Thakur, R.; Ravi, B.L. Design and Development of Microcontroller based Controlled Switching Device for Transformer. In Proceedings of the International Conference on Innovative Mechanisms for Industry Applications (ICIMIA 2017), Bengaluru, India, 21-23 February 2017; pp. 349-353.

12. Jehle, A.; Biela, J. Optimization of Hybrid Current-Injection Circuit Breakers including Mechanical Switch Limitations. In Proceedings of the 21st European Conference on Power Electronics and Applications, Genova, Italy, 2-6 September 2019; pp. 1-11.

13. Wakatsuki, N.; Yonezawa, Y. Relay Contacts of Multi-Electrodes with Timely Controlled Operation for Arc Discharge Suppression. In Proceedings of the 50th IEEE Holm Conference on Electrical Contacts, Seattle, WA, USA, 23 September 2004; pp. 474-479.

14. Chen, L.; Chen, Z. Intelligent AC Contactor with Contacts for Switching Reactive Compensation Device. In Proceedings of the APAP 2011: International Conference on Advanced Power System Automation and Protection, Beijing, China, 16-20 October 2011; pp. 781-784.

15. Collombet, M.; Lacroix, B. LV circuit-breakers confronted with harmonic, transient and cyclic currents. Cahier Tech. Merlin Gerin 2011, 182, 12.

16. Hillary-Tin, A.; Abu-Siada, M.S. Impact of Harmonics on the Performance of Over-Current Relays. In Proceedings of the APAP 2011: International Conference on Advanced Power System Automation and Protection, Beijing, China, 16-20 October 2011.

17. Kamtip, S.; Bhumkittipich, K. Comparison between Mechanical Circuit Breaker and Solid State Circuit Breaker under Abnormal Conditions for Low Voltage Systems. In Proceedings of the 18th International Conference on Electrical Machines and Systems (ICEMS), Pattaya, Thailand, 25-28 October 2015; pp. 1091-1096.

18. Liu, Y.; Cheng, D.; Ji, L.; Geng, Y. Dynamic Characteristic and Contact Bounce Analysis for an AC Contactor with PWM Controlled Coil. In Proceedings of the 53rd IEEE Holm Conference on Electrical Contacts, Pittsburgh, PA, USA, 16-19 September 2007; pp. 289-293.

19. Zong, M.; Qi, L.; Wang, X.; Zhang, Y.; Wang, S. A Review of Intelligent Contactor Design and Its Control Technology. Int. J. Control. Autom. 2016, 9, 389-402. [CrossRef]

20. Xu, Z.; Zhang, P. Intelligent Control Technology of AC Contactor. 2005 IEEE/PES Transmission \& Distribution Conference \& Exposition: Asia and Pacific, Dalian, China, 18 August 2005; pp. 1-6.

21. Avila, L.I.M.; Castatnñón, L.E.G.; Ortiz, E.R.C. An Intelligent Control Approach for Designing a Low Voltage DC Breaker. In Proceedings of the 2012 VI Andean Region International Conference, Cuenca, Ecuador, 7-9 November 2012; pp. $163-166$.

22. Lacroix, M.; Gutierrez, A. Controlled Switching and Circuit Breaker Monitoring. In Proceedings of the IEEE 37th Central America and Panama Convention (CONCAPAN XXXVII), Managua, Nicaragua, 15-17 November 2017; pp. 1-5.

23. Song, M.-G.; Kim, S.-M.; Li, K.-B. Synchronized Switching Technique for Elimination of Unexpected Output Pulses in Hybrid Active NPC inverter. In Proceedings of the 2019 IEEE 4th International Future Energy Electronics Conference (IFEEC), Singapore, 25-28 November 2019.

24. JCGM 200:2012. International Vocabulary of Metrology_Basic and General Concepts and Associated Terms (VIPM), 3rd ed.; Joint Committee for Guides in Metrology: Sèvres, France, 2012.

25. Bauchire, J.M.; Hong, D.; Rabat, H.; Riquel, G. Radiation of transient high-current arcs: Energy measurements in the optical range. J. Phys. Conf. Ser. 2012, 406. [CrossRef]

26. Xu, X.; Li, Y.; Tan, X. Research of Monitoring Switching-generated Arcing Current during Opening and Closing Process using Rogowski Coil. In Proceedings of the 2008 International Conference on Condition Monitoring and Diagnosis, Beijing, China, 21-24 April 2008.

27. Sekulic, W.R.; McNutt, P. Evaluating the Incident Energy of Arcs in Photovoltaic DC Systems: Comparison Between Calculated and Experimental Data. IEEE Trans. Ind. Appl. 2020, 56, 3224-3230. [CrossRef]

28. Porte, M.; Razafiarivelo, J.; Carvou, E.; Ben Jemaa, N. Contact heating by long arcing during connector disconnection. In Proceedings of the 51st IEEE Holm Conference on Electrical Contacts, Chicago, IL, USA, 26-28 September 2005 ; pp. 360-365.

29. Donen, T.; Takai, Y.; Ochi, S. Effect of Arcing Time with Capacitive Making Current on Contact Welding in Vacuum. In Proceedings of the 2018 28th International Symposium on Discharges and Electrical Insulation in Vacuum (ISDEIV), Greifswald, Germany, 23-28 September 2018; pp. 197-200. 
30. Murakami, M.; Ryonai, H.; Kubono, T.; Sekikawa, J. Properties of Short Arc Phenomena on AgCu Electrical Contact Pairs for Automotive Electronics Devices. In Proceedings of the 53rd IEEE Holm Conference on Electrical Contacts, Pittsburgh, PA, USA, 16-19 September 2007; pp. 145-150.

31. Swingler, J. Performance and arcing characteristics of Ag/Ni contact materials under DC resistive load conditions. IET Sci. Meas. Technol. 2011, 5, 37-45. [CrossRef]

32. Borkowski, P.; Walczuk, E. Computerized measurement stands for testing static and dynamic electrical contact welding. Measurement 2011, 44, 1618-1627. [CrossRef]

33. Smugala, D.; Bonk, M. Study of Arc Parameters of AC Relays Operating under Distorted Supply Voltage Conditions. Energies 2020, 13, 4785. [CrossRef]

34. Cho, D.-J.; Kang, J.S.; Kim, B.-J.; Jin, Y.H. An analysis of electromagnetic characteristics and mechanical load characteristics of actuator for 4 pole MC. In Proceedings of the 3rd International Conference on Electric Power Equipment-Switching Technology (ICEPE-ST), Busan, Korea, 25-27 October 2015; pp. 354-356.

35. IEEE Std 1459-2010. IEEE Standard Definitions for the Measurement of Electric Power Quantities under Sinusoidal, Nonsinusoidal, Balanced or Unbalanced Conditions; IEEE: Piscataway, NJ, USA, 2010. 